Official Journal of the Brazilian Society of Urology

\title{
PROSTATE BIOPSY: IS AGE IMPORTANT FOR DETERMINING THE PATHOLOGICAL FEATURES IN PROSTATE CANCER?
}

\author{
ALBERTO A. ANTUNES, KATIA R. LEITE, MARCOS F. DALL'OGLIO, ALEXANDRE \\ CRIPPA, LUCIANO J. NESRALLAH, MIGUEL SROUGI \\ Laboratory of Surgical and Molecular Pathology, Syrian Lebanese Hospital, Sao Paulo, SP, and Division of \\ Urology, Paulista School of Medicine, Federal University of Sao Paulo, UNIFESP, Sao Paulo, SP, Brazil
}

\begin{abstract}
Introduction: The influence of age on the aggressiveness of prostate cancer (PCa) is controversial. This study aims to assess the influence of age in determining the pathological features of biopsies from patients diagnosed with PCa.

Patients and Methods: We selected 1422 patients with clinical suspicion of PCa; among them, $547(38.5 \%)$ had received a diagnosis of adenocarcinoma. Patients were categorized into the following age groups: up to 50 years old, 51 to 60 years, 61 to 70 years, 71 to 80 years, and over 80 years. The evaluated variables were histological grade, presence of perineural invasion and estimate of tumor volume through measurement of the maximum percentage of tissue with cancer in one fragment and total percentage of tissue with cancer in the sample.

Results: The mean age of patients was 66.4 years, with age range from 32 to 94 years. The estimate of tumor volume by maximum percentage of tissue with cancer in one fragment $(p=0.064)$, total percentage of tissue with cancer in the sample $(p=0.443)$, and Gleason score $(p=0.485)$ were not statistically different in relation to the age groups under study. The presence of perineural invasion occurred more frequently among the 50 years and 81 years age groups when compared with patients aged from 51 to 60 and from 61 to 80 years $(\mathrm{p}=0.005)$.

Conclusions: Age did not represent a determining factor for pathological findings concerning Gleason score and estimate of tumor volume by the variables in use.
\end{abstract}

Key words: prostatic neoplasms; age groups; biopsy; needle; neoplasm staging; pathology

Int Braz J Urol. 2005; 31: 331-7

\section{INTRODUCTION}

Currently, prostate cancer $(\mathrm{PCa})$ is the most frequent tumor in males and the second cause of death due to cancer (1). Following the advent of prostatespecific antigen (PSA), the diagnosis of PCa began to involve individuals from increasingly younger age groups. Thus, while only approximately 0.8 to $1.1 \%$ of cases of $\mathrm{PCa}$ were diagnosed in men under 50 years old during the ' 70 s and ' 80 s, this rate today reaches $4 \%$ of cases $(2,3)$.
Determining the aggressiveness of PCa is fundamental for selecting the proper management, and studies assessing the influence of age on tumor aggressiveness have showed controversial results. Though most studies have historically demonstrated that younger men have more aggressive and lethal tumors $(4,5)$, more recently other authors have pointed to a relationship between advanced age and highgrade, more voluminous lesions $(6,7)$.

However, the majority of recent studies assessing the influence of age on pathological features 
of PCa involve only patients that are candidates to curative treatments such as radical prostatectomy (RP) or radiotherapy. Such studies have shown conflicting results, since while some authors report that younger patients are more likely to have favorable pathological findings and higher chances of cure when treated by RP $(2,3,6,8,9)$, other have demonstrated that they present similar results, or even a higher likelihood of biochemical recurrence among the oldest individuals when treated by RP or radiotherapy $(10,11)$.

Pathological data from the biopsy, such as Gleason score, tumor volume and the presence of perineural invasion, are factors admittedly associated with the prognosis of patients diagnosed with $\mathrm{PCa}$ (12-17). Thus, since more and more patients from younger age groups are being diagnosed with $\mathrm{PCa}$, the knowledge of different features of tumors in this group of patients gains enormous importance.

This study aims to assess the influence of age in determining the pathological features of biopsy in patients diagnosed with PCa.

\section{MATERIALS AND METHODS}

During the period from January 2001 and December 2003, we analyzed samples of prostate biopsies from 1422 patients with clinical suspicion of $\mathrm{PCa}$ due to an increase in serum PSA or a noticeable change during digital rectal examinations. Of these, $547(38.5 \%)$ were diagnosed with adenocarcinoma. Among patients with this diagnosis, 245 (45\%) received the definitive diagnosis of adenocarcinoma only after the slide was re-viewed, and whose initial analysis showed findings such as prostate intra-epithelial neoplasia (PIN), atypical small acinar proliferation (ASAP) or presence of adenocarcinoma in less than $5 \%$ of the entire sample. After excluding 1 patient whose Gleason score was not available, we totaled 546 patients.

For pathological analysis, fragments of prostate biopsy were placed in special cassettes and dispatched in $10 \%$ formalin. Next, they were identified in relation to biopsy location, numbered, processed for inclusion in paraffin and divided into $5-\mu \mathrm{m}$ sections. The same pathologist evaluated all slides and tumors were graded according to Gleason score.
Patients were categorized into the following age groups: up to 50 years of age, 51 to 60 years of age, 61 to 70 years of age, 71 to 80 years of age and over 80 years of age. Variables in use were: histological grade; presence of perineural invasion; and estimate of tumor volume by measuring the maximum percentage of tissue with cancer in one fragment, and the total percentage of tissue with cancer in the sample.

The statistical assessment was performed using the Pearson qui-square and Kruskal-Wallis tests. $P$ values $<0.05$ were considered statistically significant.

\section{RESULTS}

The mean age of patients was 66.4 years, with an age range of from 32 to 94 years. Table-1 shows the distribution of patients diagnosed with prostate adenocarcinoma in relation to the age groups. Only $5 \%$ of the patients were aged 50 years or less. The mean number of biopsied fragments was 11.3 , with a range of from 1 to 31 fragments.

In relation to estimate of tumor volume, information regarding the maximum percentage of tissue with cancer in one sample fragment was available for 543 patients. The median for this occurrence was $70 \%$, with a range of from 1 to $100 \%$. The total percentage of tissue with cancer in the sample was available for 377 patients; the median was $12 \%$, with a range of from $0.4 \%$ to $100 \%$. An assessment of Gleason score was available for all patients. The median score was 7 , with a range of from 4 to 10 . Table- 2 shows the distribution of patients according

Table 1 - Patient distribution according to age group in years.

\begin{tabular}{lc}
\hline Age Group & N Patients $(\%)$ \\
\hline$\leq 50$ & $30(5)$ \\
$51-60$ & $116(21)$ \\
$61-70$ & $205(37)$ \\
$71-80$ & $168(31)$ \\
$\geq 81$ & $27(5)$ \\
Total & $546(100)$ \\
\hline
\end{tabular}


Table 2 - Distribution of Gleason scores in categories of well differentiated, moderately differentiated and poorly differentiated tumors.

\begin{tabular}{lc}
\hline Gleason Score & N Patients $(\%)$ \\
\hline 2 a 6 & $214(39)$ \\
7 & $156(29)$ \\
8 a 10 & $176(32)$ \\
Total & $546(100)$ \\
\hline
\end{tabular}

to scores from 2 to 6,7 and from 8 to 10 . Information concerning perineural invasion was available for 539 patients, and it was present in 137 (25\%).

When assessing the relationship between age groups and the aforementioned features, we observed that, in relation to the maximum percentage of cancer in one fragment, the $\leq 50$ year and $\geq 81$ year age groups seem to present, on average, the same maximum percentage of cancer in one fragment, and it appears to be higher than the percentage observed in the 51 to 80 year age group. We also observed that the 61 to 70 year age group showed the highest variability. Through the Kruskal-Wallis test, the observed differences have shown to be only marginally significant $(\mathrm{p}=0.064)($ Table- 3$)$.

According to the total percentage of cancer in the sample, we observed that the $\leq 50$ year and $\geq 81$ year age groups presented, on average, higher values than other age groups. We also observed higher variability in these 2 age groups when compared with values from other age groups. Through the Kruskal-Wallis test, no statistically significant difference was observed in the total percentage of cancer in the sample between the age groups under assessment $(p=0.443)($ Table-4).

In relation to Gleason scores, despite $47 \%$ of patients aged up to 50 years presenting Gleason scores 2 and 6 , and $48 \%$ of patients over 80 years presenting

Table 3 - Descriptive measures of maximum \% of cancer in one fragment according to age group (Kruskal-Wallis, $p=0.064)$.

\section{Age Group (Years)}

\begin{tabular}{lccccc} 
& $\mathbf{5 0}$ & $\mathbf{5 1 - 6 0}$ & $\mathbf{6 1 - \mathbf { 7 0 }}$ & $\mathbf{7 1 - 8 0}$ & $\mathbf{2 8 1}$ \\
\hline Mean & $75.5 \%$ & $64.6 \%$ & $63.2 \%$ & $65.8 \%$ & $76.5 \%$ \\
Standard Deviation & $29.5 \%$ & $28.3 \%$ & $32.4 \%$ & $28.6 \%$ & $28.1 \%$ \\
Median & $90 \%$ & $60 \%$ & $70 \%$ & $70 \%$ & $90 \%$ \\
Minimum & $1 \%$ & $1 \%$ & $1 \%$ & $5 \%$ & $10 \%$ \\
Maximum & $100 \%$ & $100 \%$ & $100 \%$ & $100 \%$ & $100 \%$ \\
N. Observations & 29 & 116 & 204 & 168 & 26 \\
\hline
\end{tabular}

Table 4-Descriptive measures of total \% of cancer in the sample according to age group (Kruskal-Wallis, $p=0.443)$.

\section{Age Group (Years)}

\begin{tabular}{lccccc} 
& $\mathbf{5 0}$ & $\mathbf{5 1 - 6 0}$ & $\mathbf{6 1 - 7 0}$ & $\mathbf{7 1 - 8 0}$ & $\mathbf{8 1}$ \\
\hline Mean & $23.9 \%$ & $19.7 \%$ & $17.4 \%$ & $18.0 \%$ & $24.2 \%$ \\
Standard Deviation & $25.3 \%$ & $18.9 \%$ & $18.6 \%$ & $19.2 \%$ & $28.9 \%$ \\
Median & $16.5 \%$ & $14.0 \%$ & $10.0 \%$ & $12.0 \%$ & $16.0 \%$ \\
Minimum & $1 \%$ & $0.8 \%$ & $0.4 \%$ & $0.6 \%$ & $1.3 \%$ \\
Maximum & $100 \%$ & $90 \%$ & $100 \%$ & $100 \%$ & $100 \%$ \\
N. Observations & 24 & 92 & 137 & 109 & 15 \\
\hline
\end{tabular}


scores between 8 and 10, these findings were not statistically significant $(\mathrm{p}=0.485)$, (Table-5).

In relation to the presence of perineural invasion, Table- 6 shows that there was association concerning age group $(\mathrm{p}=0.005)$. In order to assess where this association occurs, we performed the quisquare test, which demonstrated that the $\leq 50$ year and $\geq 81$ year age groups showed the same percentage of perineural invasion ( $p=0.621)$. The 61 to 70 year and from 71 to 80 year age groups showed the same distribution of perineural invasion $(\mathrm{p}=0.479)$. Thus, according to these results, we could say that, on average, the percentage of perineural invasion was $41 \%$ for the $\leq 50$ year and $\geq 81$ year age groups, $15 \%$ for the from 51 to 60 year group, and this percentage can be estimated at $26 \%$ for the 61 to 80 year group $(p=0.001)$.

\section{COMMENTS}

In the present study, the authors have demonstrated that the data from the biopsy, such as estimate of tumor volume by maximum percentage of tissue with cancer in one fragment and total percentage of tissue with cancer in the sample as well as Gleason score, were not statistically different in relation to the age groups under study. On the other hand, the presence of perineural invasion occurred more frequently among the $\leq 50$ year and $\geq 81$ year age groups when compared with patients aged between 51 and 60 and between 61 and 80 .

Tumor volume, the presence of perineural invasion, and Gleason score are known to be associated with prognosis in patients diagnosed with $\mathrm{PCa}$ (12-17). There is no agreement concerning the best

Table 5 - Patient distribution according to age group and Gleason scores (qui-square, $p=0.485$ ).

\begin{tabular}{lcrrr}
\hline & \multicolumn{5}{c}{ Gleason } \\
Age Group (Years) & $\mathbf{2 ~ a ~ 6 ~}$ & $\mathbf{7}$ & $\mathbf{8 ~ a ~ 1 0}$ & \multicolumn{1}{c}{ Total } \\
\hline$\leq 50$ & $14(47 \%)$ & $7(23 \%)$ & $9(30 \%)$ & $30(100 \%)$ \\
51 a 60 & $52(45 \%)$ & $35(30 \%)$ & $29(25 \%)$ & $116(100 \%)$ \\
61 a 70 & $78(38 \%)$ & $59(29 \%)$ & $68(33 \%)$ & $205(100 \%)$ \\
71 a 80 & $63(37 \%)$ & $48(29 \%)$ & $57(34 \%)$ & $168(100 \%)$ \\
$\geq 81$ & $7(26 \%)$ & $7(26 \%)$ & $13(48 \%)$ & $27(100 \%)$ \\
Total & $214(39 \%)$ & $156(29 \%)$ & $176(32 \%)$ & $546(100 \%)$ \\
\hline
\end{tabular}

Table 6 - Patient distribution according to age group and presence or absence of perineural invasion (qui-square, $p=0.005)$.

\begin{tabular}{lcrr}
\hline & \multicolumn{2}{c}{ Perineural Invasion } & \\
Age Group (years) & Present & Absent & \multicolumn{1}{c}{ Total } \\
\hline$\leq 50$ & $11(38 \%)$ & $18(62 \%)$ & $29(100 \%)$ \\
$51-60$ & $17(15 \%)$ & $98(85 \%)$ & $115(100 \%)$ \\
$61-70$ & $50(25 \%)$ & $151(75 \%)$ & $201(100 \%)$ \\
$71-80$ & $47(28 \%)$ & $120(72 \%)$ & $167(100 \%)$ \\
$\geq 81$ & $12(44 \%)$ & $15(56 \%)$ & $27(100 \%)$ \\
Total & $137(25 \%)$ & $402(75 \%)$ & $539(100 \%)$ \\
\hline
\end{tabular}


method for measuring tumor volume (18). One study analyzing 190 biopsies in men with PCa undergoing RP showed that the percentage of tissue with cancer on biopsy was the main predictive factor for postoperative biochemical recurrence, surpassing even serum PSA and Gleason score. Similarly, the percentage of tissue with cancer is an independent variable of risk for involvement of seminal vesicles and extraprostatic disease (19).

The presence of perineural invasion in the prostate biopsy specimen from patients diagnosed with PCa represents an independent variable of risk for biochemical recurrence in patients regarded as high and low risk and treated by RP or radiotherapy $(16,17)$. One study of 381 patients with localized PCa undergoing radiotherapy has demonstrated that 5-year disease-free survival rates were $50 \%$ versus $80 \%$ in low-risk patients and $29 \%$ versus $53 \%$ in high-risk patients with and without perineural invasion respectively (16). Our study has revealed that the percentage of perineural invasion was $41 \%$ in the $\leq 50$ year and $\geq 81$ year age groups, $15 \%$ for the between 51 to 60 year group, and this percentage was estimated at $26 \%$ for the between 61 and 80 year group $(p=0.001)$.

Histological grade as defined by the Gleason score, together with serum PSA, is regarded as the main prognostic factor for post-operative tumor progression by many authors (12). Recently, one study of 3478 patients undergoing RP has demonstrated that 10 -year disease-free survival was estimated in $77 \%$, $64 \%, 50 \%$ and $32 \%$ of patients with Gleason score of from 2 to $6,7(3+4), 7(4+3)$ and from 8 to 10 respectively (20). In our study, there was a balance between age groups and Gleason scores.

Analyses of the relationship between age and PCa aggressiveness have shown controversial results in the literature. Studies performed before the PSA era point to a relationship between younger patients and more aggressive tumors $(4,5)$. Other authors have found no differences in recurrence rates of the disease among younger patients. One study comparing 46 patients younger than 60 years of age and 193 patients aged between 65 and 74 years of age showed that both groups had similar behavior when compared for cellular differentiation, presence of metastases and survival (10). Other authors have demonstrated that patients younger than 50 years with PCa presented symptoms, histological grades and stages that were similar to the older population with PCa (11).

More recent studies, however, have shown that younger patients with PCa present a higher number of organ-confined tumors and better response to treatment. One study assessing the influence of age on pathological stage of 444 men with localized PCa undergoing RP has revealed that there were no agerelated differences for clinical stages A1, A2 and B2; however, when patients classified as B1 (disease confined to less than 1 lobe) were assessed in relation to age, we observed a statistically significant trend towards a progressive increase in pathological stage with increasing age. A trend towards higher Gleason scores was observed in older patients as well. Mean Gleason score was 5, 6 and 7 for patients aged from 34 to 49 years, 50 to 59 years and 60 to 75 years respectively (7).

Herold et al. (21) studied the correlation between patient's age and occurrence of distant metastases in 567 patients receiving radiotherapy as definitive treatment for PCa. They split the population into a group aged up to 65 years, and another aged over 65 years. Patient's age was an independent predictive factor for metastasis on univariate and multivariate analyses, with patients older than 65 years presenting a higher number of distant metastases. Carter et al. (6) divided a population of 492 patients with T1c stages undergoing RP into groups of from 40 to 50 years (69 patients), 51 to 60 years (227 patients) and 61 to 73 years (196 patients). We observed that there was a percentage increase in a Gleason score of 7 with increasing age and similarly, higher probability of detecting disease in a potentially curable stage among younger patients. Subsequently, Khan et al. (2) analyzed 2897 patients with PCa undergoing RP and compared the under 50 years of age cases (341 patients) with 50 years or older cases (2556 patients). Younger patients showed a lower incidence of extraprostatic extension ( $25 \%$ versus $31 \%$ ), involvement of seminal vesicles ( $2 \%$ versus $6 \%$ ), positive surgical margins (3\% versus $9 \%$ ) and a trend towards higher disease-free survival rates.

The exact mechanisms explaining the characteristic differences of $\mathrm{PCa}$ among age groups are 
not quite understood yet. Recent studies point to lower Gleason scores among younger patients, suggesting that the elderly have biologically more aggressive tumors (8). Some studies stress the difficulties for accurately staging the PCa in the elderly, since these patients have a higher frequency of benign prostate hyperplasia (BPH), and thus, younger men have more easily palpable tumors than older ones, where the lesions can be masked by BPH (7).

Biopsy studies have shown that PCa starts between the 4th and 5th decades of life and, with increasing age, the frequency of high-grade and more voluminous tumors increases as well, which are variables with prognostic significance as previously shown (22). In the present study, the fact that younger patients present tumor features similar to older patients can suggest that, in its natural history, the $\mathrm{PCa}$ has a more aggressive behavior from the start, contrarily to the theory that more aggressive tumors result from an evolving process of initially well-differentiated tumors over the years.

One advantage of the present study is that, contrary to recent studies assessing the influence of age on $\mathrm{PCa}$, it included patients undergoing prostate biopsy with low, intermediate and high-grade tumors who subsequently received several kinds of treatment. The fact that the remaining studies involve patients that are candidates for curative treatment for cancer means that many patients with poorly differentiated tumors and some elderly patients with insignificant tumors could have been excluded from such analyses, thus restricting their interpretation.

Finally, we have concluded that age does not represent a determining factor for pathological findings relative to Gleason score and estimate of tumor volume by the variables in use, and that the presence of perineural invasion seems to occur less frequently among patients younger than 50 or older than 80 years. However, due to non-inclusion of serum PSA analysis and the small number of patients younger than 50 and older than 80 years, these results should be carefully interpreted. New studies assessing biopsies from patients with uniform distribution between the age groups should be performed in order to determine the real influence of age on $\mathrm{PCa}$ differentiation.

\section{REFERENCES}

1. Jemal A, Tiwari RC, Murray T, Ghafoor A, Samuels A, Ward E, et al.: Cancer statistics, 2004. CA Cancer J Clin. 2004; 54: 8-29.

2. Khan MA, Han M, Partin AW, Epstein JI, Walsh PC: Long-term cancer control of radical prostatectomy in men younger than 50 years of age: update 2003. Urology. 2003; 62: 86-91; discussion 91-2.

3. Smith CV, Bauer JJ, Connelly RR, Seay T, Kane C, Foley J, et al.: Prostate cancer in men age 50 years or younger: a review of the Department of Defense Center for Prostate Disease Research multicenter prostate cancer database. J Urol. 2000; 164: 1964-7.

4. Tjaden HB, Culp DA, Flocks RH: Clinical adenocarcinoma of the prostate in patients under 50 years of age. J Urol. 1965; 93: 618-21.

5. Johnson DE, Lanieri JP Jr, Ayala AG: Prostatic adenocarcinoma occurring in men under 50 years of age. $\mathrm{J}$ Surg Oncol. 1972; 4: 207-16.

6. Carter HB, Epstein JI, Partin AW: Influence of age and prostate-specific antigen on the chance of curable prostate cancer among men with non-palpable disease. Urology. 1999; 53: 126-30.

7. Alexander RB, Maguire MG, Epstein JI, Walsh PC: Pathological stage is higher in older men with clinical stage B1 adenocarcinoma of the prostate. J Urol. 1989; 141: 880-2.

8. Freedland SJ, Presti JC Jr, Kane CJ, Aronson WJ, Terris MK, Dorey F, et al.: Do younger men have better biochemical outcomes after radical prostatectomy? Urology. 2004; 63: 518-22.

9. Obek C, Lai S, Sadek S, Civantos F, Soloway MS: Age as a prognostic factor for disease recurrence after radical prostatectomy. Urology. 1999; 54: 533-8.

10. Harrison GS: The prognosis of prostatic cancer in the younger man. Br J Urol. 1983; 55: 315-20.

11. Aprikian AG, Zhang ZF, Fair WR: Prostate adenocarcinoma in men younger than 50 years. A retrospective review of 151 patients. Cancer. 1994; 74: 1768-77.

12. Epstein JI, Walsh PC, Carmichael M, Brendler CB: Pathologic and clinical findings to predict tumor extent of nonpalpable (stage T1c) prostate cancer. JAMA. 1994; 271: 368-74.

13. D'Amico AV, Whittington R, Malkowicz SB, Schultz $\mathrm{D}$, Fondurulia J, Chen MH, et al.: Clinical utility of the percentage of positive prostate biopsies in defining biochemical outcome after radical prostatectomy for patients with clinically localized prostate cancer. $\mathbf{J}$ Clin Oncol. 2000; 18: 1164-72. 
14. Grossfeld GD, Latini DM, Lubeck DP, Broering JM, Li YP, Mehta SS, et al.: Predicting disease recurrence in intermediate and high-risk patients undergoing radical prostatectomy using percent positive biopsies: results from PCaSURE. Urology. 2002; 59: 560-5.

15. Eichelberger LE, Koch MO, Daggy JK, Ulbright TM, Eble JN, Cheng L: Predicting tumor volume in radical prostatectomy specimens from patients with prostate cancer. Am J Clin Pathol. 2003; 120: 386-91.

16. Beard CJ, Chen MH, Cote K, Loffredo M, Renshaw AA, Hurwitz M, et al.: Perineural invasion is associated with increased relapse after external beam radiotherapy for men with low-risk prostate cancer and may be a marker for occult, high-grade cancer. Int J Radiat Oncol Biol Phys. 2004; 58: 19-24.

17. D'Amico AV, Wu Y, Chen MH, Nash M, Renshaw AA, Richie JP: Perineural invasion as a predictor of biochemical outcome following radical prostatectomy for select men with clinically localized prostate cancer. J Urol. 2001; 165: 126-9.

18. Freedland SJ, Aronson WJ, Terris MK, Kane CJ, Amling CL, Dorey F, et al.: The percentage of prostate needle biopsy cores with carcinoma from the more involved side of the biopsy as a predictor of prostate specific antigen recurrence after radical prostatectomy: results from the Shared Equal Access Regional Cancer Hospital (SEARCH) database. Cancer. 2003; 98: 2344-50.

19. Freedland SJ, Csathy GS, Dorey F, Aronson WJ: Percent prostate needle biopsy tissue with cancer is more predictive of biochemical failure or adverse pathology after radical prostatectomy than prostate specific antigen or Gleason score. J Urol. 2002; 167: 516-20.

20. Roehl KA, Han M, Ramos CG, Antenor JA, Catalona WJ: Cancer progression and survival rates following anatomical radical retro-pubic prostatectomy in 3,478 consecutive patients: long-term results. J Urol. 2004; 172: $910-4$

21. Herold DM, Hanlon AL, Movsas B, Hanks GE: Agerelated prostate cancer metastases. Urology. 1998; 51: 985-90.

22. Stamey TA, Raimondo M, Yemoto CM, McNeal JE, Johnstone LM: Effect of ageing on morphologic and clinical predictors of prostate cancer progression. The Prostate J. 2000; 2: 157.

Received: January 25, 2005 Accepted after revision: June 8, 2005

\section{Correspondence address:}

Dr. Alberto A. Antunes

Rua Dr. Diogo de Faria, 1201

Sao Paulo, SP, 04037-004, Brazil

E-mail: betoazoubel@yahoo.com.br 